\title{
A successful treatment for metastatic liver tumors from endocrine carcinoma of the stomach
}

\author{
MASAKO NISHIMURA $^{1,3}$ and YOSHIHIDE FUJIYAMA ${ }^{2}$ \\ ${ }^{1}$ Department of Gastroenterology, Yawata Central Hospital, Yawata-city, Kyoto; \\ ${ }^{2}$ Department of Gastroenterology, Shiga University of Medical Science, Otsu, Japan
}

Received October 5, 2006; Accepted December 4, 2006

\begin{abstract}
Endocrine carcinomas (ECs) of the stomach reveal prominently aggressive behavior and have poor prognoses. Optimal treatments for gastric ECs have not been established because of the rarity of EC. In general, patients with gastric ECs die within a year of diagnosis in spite of surgical resections and subsequent chemotherapies. Liver metastases are the most common cause of death in gastric ECs, and their control is very important for improving the poor prognosis associated with the disease. In the present report, we describe a case in which a subject with stomach EC was diagnosed at an early stage. However, multiple liver metastases occurred soon after curative surgical resection and were treated via hepatic arterial infusion (HAI) with a combination of cisplatin and 5-fluorouracil. Consequently, the tumors almost completely disappeared. HAI therapy is a useful treatment for multiple metastatic liver tumors from gastric ECs devoid of metastases in other organs. Previously published therapies used to treat ECs of the stomach, including the ones used in the current case, are also discussed herein.
\end{abstract}

\section{Introduction}

Endocrine carcinomas (ECs) can arise in any gastrointestinal (GI) tract, however, their occurence is infrequent (1). ECs of the stomach account for only 0.1 to $0.9 \%$ of all gastric carcinomas $(2,3)$, and reveal prominently aggressive behavior, which differ from conventional gastric carcinomas $(1,4)$. In general, EC patients have very poor prognoses in spite of surgical resections and subsequent chemotherapies, and die within a year of diagnosis $(1,4,5)$. However, with the occurrence of new anti-cancer agents and improvements in interventional treatments (6), the number of long-term survivors with gastric ECs has increased. In the current study, we

Correspondence to: Dr Masako Nishimura, ${ }^{3}$ Present address: Department of Gastroenterology, Yawata Central Hospital, Gotan-da 39-1, Yawata, Yawata-city, Kyoto 614-8071, Japan

E-mail: nishimu@hkg.odn.ne.jp

Key words: endocrine carcinoma of the stomach, metastatic liver tumors, hepatic arterial infusion, low-dose administration of cisplatin and 5-fluorouracil describe a case in which a subject with stomach EC, had multiple metastatic liver tumors which disappeared almost completely after hepatic arterial infusion (HAI) chemotherapy with the continuous administration of cisplatin (CDDP) and 5-fluorouracil (5-FU). In the 'Discussion', the previously reported treatments for ECs of the stomach are also reviewed.

\section{Case report}

Despite the lack of abdominal symptoms, a 76-year-old woman displayed a polypoid lesion on a screening barium meal study. A subsequent upper gastrointestinal endoscopy revealed an early-stage gastric carcinoma (a superficially spreading-type carcinoma with a protruding region) in the lesser curvature of the stomach body (Fig. 1). A total gastrectomy with a regional lymph node (LN) dissection was performed, and postoperative pathological findings showed well-, and in some parts moderately-differentiated tubular adenocarcinomas with no LN metastases. According to the UICC TNM classification, the clinical stage was T1, N0, M0, and stage IA. Two months after the surgical resection, multiple liver tumors lacking swollen LNs were disclosed on an abdominal computed tomographic (CT) scan (Fig. 2A). No other tumors presented as primary foci in any other tissue except the liver. Biopsied specimens from the liver tumors revealed poorly differentiated carcinomas, which showed solid growth without glandular components. Additional histological examinations disclosed positive immunostaining for cytokeratin, the epithelial membrane antigen (EMA) and the neural cell adhesion molecule (NCAM) in the liver tumors, while an electron microscopic study showed multiple dense-cored granules in the cytoplasm of the poorly differentiated carcinoma cells (Fig. 3A), suggesting that they were ECs. Re-examinations of the microscopic findings of the resected stomach defined poorly differentiated carcinomas, which revealed solid growth with gland-like structures, in a small area inside of extensively distributed tubular adenocarcinomas (Fig. 3B). Histological examinations also revealed positive responses for cytokeratin, EMA, NCAM and small electron-dense granules in the poorly differentiated carcinoma cells of the stomach. Under the diagnosis that the multiple liver tumors were metastases from composite type gastric ECs, intensive chemotherapy using HAI (20 mg CDDP for $1 \mathrm{~h}$ and $250 \mathrm{mg} 5$-FU for $4 \mathrm{~h}$, on days 1 to 5) via a subcutaneously implanted port, was performed for 3 continuous weeks, and 


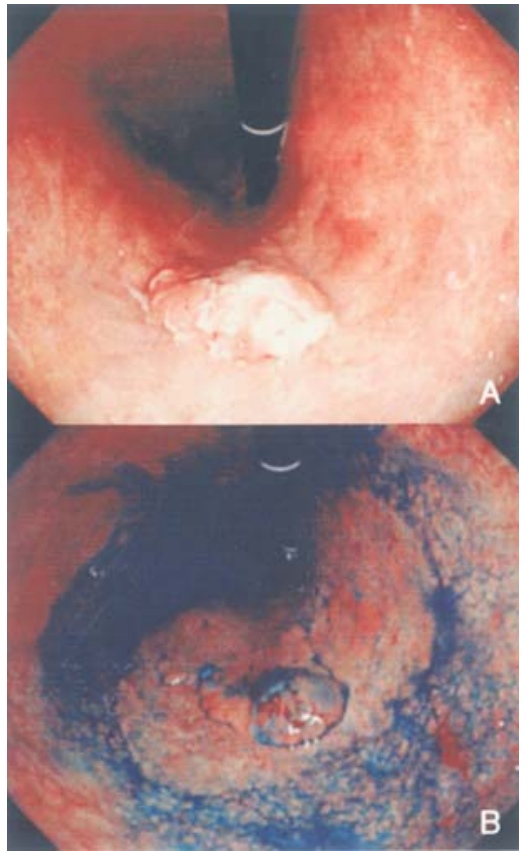

Figure 1. An upper gastrointestinal endoscopy revealed a superficially spreading-type tumor with a protruding region in the lesser curvature of the stomach body (A). After spraying with indigo dye, a widespread tumor with a mildly elevated margin became clear (B).

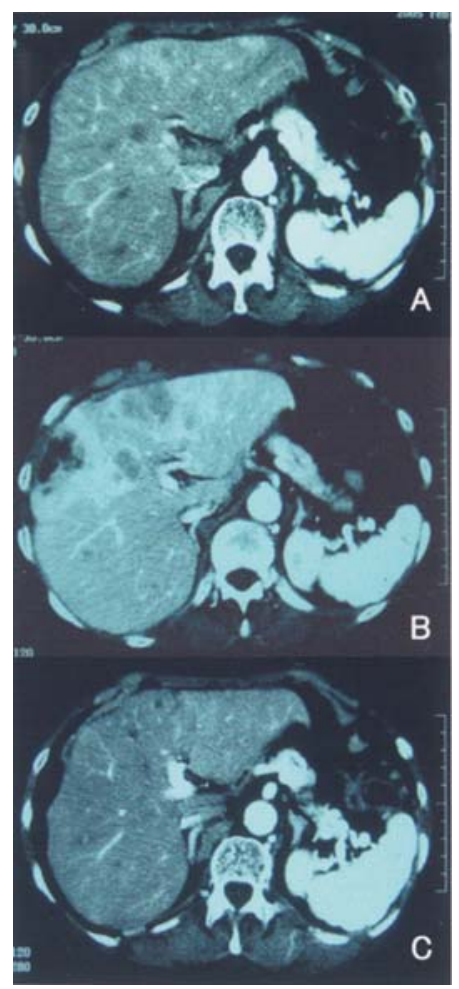

Figure 2. Multiple liver tumors were revealed in the arterial phase of a dynamic computed tomograhic scan (A), which became massive before the start of chemotherapy using hepatic arterial infusion. (B). After the end of the first round of chemotherapy, the massive liver tumors almost completely disappeared, and no new lesions were visible (C).

subsequently discontinued due to drug toxicity, nausea and vomiting. Even though the multiple liver tumors were growing to a large size before the start of chemotherapy (Fig. 2B),

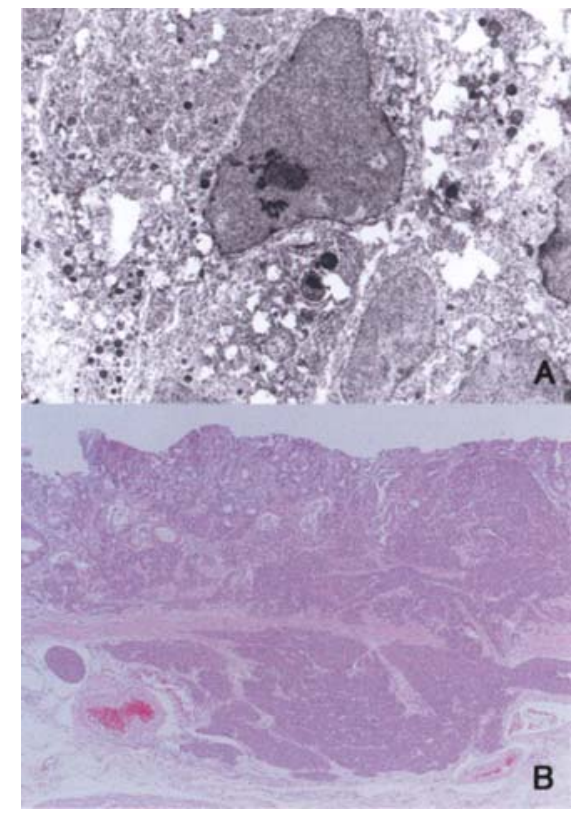

Figure 3. In electron microscopic examinations, poorly differentiated carcinomas in the liver showed multiple dense-cored granules in the cytoplasm of the tumor cells (A) (x4000). Poorly differentiated carcinomas were revealed with solid growth and gland-like structures, underlying widely distributed well-differentiated tubular adenocarcinomas in the stomach (B) (H\&E, x40).

these tumors disappeared almost completely 2 weeks after the end of the HAI therapy (Fig. 2C). Soon, the patient was discharged and was followed-up in an outpatient clinic. She underwent HAI therapy with the administration of $20 \mathrm{mg}$ CDDP and $250 \mathrm{mg}$ 5-FU, once a week. However, 3 months following her hospital discharge, recurrences of liver tumors and new metastatic lesions, including those in the lung, pubic bone and para-aortic LNs, were disclosed on CT scans of the chest, abdomen and pelvis. A second round of chemotherapy using $80 \mathrm{mg} \mathrm{S}-1$ on days 1 to 28 , and the intravenous administration of $30 \mathrm{mg}$ CDDP on days 7, 14, 21, and 28, was started immediately. Unfortunately, the diffuse liver tumor recurrences progressed, and the subject's condition worsened. She developed jaundice, and died of liver failure 10 months after surgery.

The patient had provided informed consent for liver biopsies, which were carried out to histologically type the tumors, in order to decide upon subsequent therapy.

\section{Discussion}

Bleak prognoses associated with stomach ECs are caused by prominent propensities for carcinomic metastases, which originate in the bottom of the gastric glands, spreading into the lymphatic and/or blood vessels even during the early stage of the disease $(4,7)$. An optimal treatment for gastric ECs has not been established because of the rarity of the disease. However, in general, operable cases can undergo surgical resections of the invaded organs, followed by intensive chemotherapy. In cases with metastatic brain tumors, which are a common cause of death in gastric ECs, cranial radiation can be employed. The clinicopathological characteristics and the chemotherapeutic regimen for gastric ECs are summarized in 
Table I. Clinicopathological characteristics and chemotherapeutic regimen in 36 reported cases with gastric endocrine carcinoma.

\begin{tabular}{|c|c|c|c|c|c|c|c|c|c|c|c|}
\hline $\begin{array}{l}\text { Case } \\
\text { no. }\end{array}$ & Year & Age/sex & Stage & $\begin{array}{l}\text { Adeno- } \\
\text { carcinoma } \\
\text { component }\end{array}$ & $\begin{array}{l}\text { Chemotherapeutic } \\
\text { regimen }\end{array}$ & Response & $\begin{array}{l}\text { Concomitant } \\
\text { treatment }\end{array}$ & $\begin{array}{l}\text { Site of metastasis } \\
\text { or recurrence }\end{array}$ & Status & $\begin{array}{l}\text { Follow-up } \\
\text { (month) }\end{array}$ & Refs. \\
\hline 1 & 1988 & $74 / \mathrm{M}$ & LD (early) & Yes & 5-FU/OK432 & PD & TG & Liver & DOD & 6 & (7) \\
\hline \multirow[t]{2}{*}{2} & \multirow[t]{2}{*}{1990} & \multirow[t]{2}{*}{$42 / \mathrm{M}$} & \multirow[t]{2}{*}{ ED } & \multirow[t]{2}{*}{ No } & i) $\mathrm{CPA} / \mathrm{DXR} / \mathrm{VCR}$ & PR & PG, gastro- & \multirow[t]{2}{*}{ Liver, LN } & & & \\
\hline & & & & & ii) CDDP/VP16 & PD & jejunostomy & & DOD & 10 & (11) \\
\hline 3 & 1991 & $59 / \mathrm{M}$ & LD (early) & No & MMC/oral tegafur & ND & SG & None & Alive, NED & 20 & (4) \\
\hline 4 & 1991 & $72 / \mathrm{M}$ & LD (early) & Yes & MMC/oral tegafur & ND & TG & None & Alive, NED & 13 & (4) \\
\hline 5 & 1991 & $59 / \mathrm{M}$ & LD (early) & Yes & CDDP/DXR & ND & SG, RT & $\begin{array}{l}\text { Liver, lung, } \\
\text { brain, LN }\end{array}$ & DOD & 18 & (4) \\
\hline 6 & 1991 & $57 / \mathrm{M}$ & LD (advanced) & No & MMC/oral tegafur & ND & TG & Liver & DOD & 5 & (4) \\
\hline 7 & 1991 & $58 / \mathrm{M}$ & LD (advanced) & No & MMC/oral tegafur & ND & TG & Liver & DOD & 9 & (4) \\
\hline 8 & 1991 & $59 / \mathrm{M}$ & LD (advanced) & No & MMC/oral tegafur & ND & SG & $\begin{array}{l}\text { Liver, lung, } \\
\text { brain, LN }\end{array}$ & DOD & 11 & (4) \\
\hline 9 & 1991 & $73 / \mathrm{F}$ & LD (advanced) & No & MMC/oral tegafur & ND & TG & Liver & DOD & 9 & (4) \\
\hline 10 & 1991 & $67 / \mathrm{F}$ & LD (advanced) & No & MMC/oral tegafur & ND & SG & $\begin{array}{l}\text { Liver, lung, brain, } \\
\text { bone, LN }\end{array}$ & DOD & 6 & (4) \\
\hline 11 & 1991 & $71 / \mathrm{M}$ & LD (advanced) & No & MMC/oral tegafur & ND & SG & Liver & DOD & 10 & (4) \\
\hline 12 & 1991 & $54 / \mathrm{M}$ & LD (advanced) & Yes & MMC/oral tegafur & ND & SG, RT & $\begin{array}{l}\text { Liver, lung, } \\
\text { brain, LN }\end{array}$ & AWD & 18 & (4) \\
\hline 13 & 1991 & $73 / \mathrm{M}$ & LD (advanced) & Yes & MMC/oral tegafur & ND & SG & Liver & DOD & 8 & (4) \\
\hline 14 & 1991 & 79/M & LD (advanced) & Yes & MMC/oral tegafur & ND & SG & $\begin{array}{l}\text { Liver, lung, } \\
\text { brain, LN }\end{array}$ & DOD & 13 & (4) \\
\hline 15 & 1991 & 64/M & LD (advanced) & Yes & MMC/oral tegafur & ND & SG & Liver & DOD & 8 & (4) \\
\hline 16 & 1991 & $74 / \mathrm{F}$ & LD (advanced) & Yes & MMC/oral tegafur & ND & SG & None & Alive, NED & 6 & (4) \\
\hline 17 & 1991 & $81 / \mathrm{F}$ & LD (advanced) & Yes & MMC/oral tegafur & ND & SG, RT & $\begin{array}{l}\text { Liver, lung, brain, } \\
\text { skin, LN }\end{array}$ & DOD & 22 & (4) \\
\hline 18 & 1991 & $76 / \mathrm{F}$ & LD (advanced) & Yes & MMC/oral tegafur & ND & SG & $\begin{array}{l}\text { Liver, lung, } \\
\text { skin, LN }\end{array}$ & DOD & 6 & (4) \\
\hline 19 & 1991 & $69 / \mathrm{M}$ & LD (advanced) & Yes & MMC/oral tegafur & ND & SG & Liver & DOD & 7 & (4) \\
\hline 20 & 1994 & $69 / \mathrm{M}$ & ED & No & $\begin{array}{l}\text { 5-FU/EPI using HAI/ } \\
\text { tegafur uracil/OK432 }\end{array}$ & PD & TG & Liver & AWD & 8 & (17) \\
\hline 21 & 1997 & $31 / \mathrm{M}$ & ED & ND & $\begin{array}{l}\text { CDDP/CPA/EPI/ } \\
\text { VP16/VCR }\end{array}$ & $\mathrm{CR}$ & PBSCT & Bone & Alive, NED & 14 & (18) \\
\hline \multirow[t]{2}{*}{22} & 1997 & $54 / \mathrm{M}$ & LD (advanced) & ND & $\begin{array}{l}\text { i) CPA/DXR/VP16 } \\
\text { ii) Carboplatin/MTX, } \\
\text { CPA/DXR/VP16 }\end{array}$ & $\begin{array}{l}\mathrm{CR} \\
\mathrm{NC} \text { or PD }\end{array}$ & None & None & & & \\
\hline & & & & & $\begin{array}{l}\text { iii) } \mathrm{VCR} / \text { chlorambucil/ } \\
\text { dexamethasone }\end{array}$ & PD & RT (for stomach) & & DOD & 23 & (19) \\
\hline 23 & 1998 & $70 / \mathrm{F}$ & ED & Yes & CDDP/VP16/DXR & $\mathrm{CR}$ & DG, hepatectomy & Liver & Alive, NED & 26 & (8) \\
\hline 24 & 1998 & $71 / \mathrm{M}$ & ED & Yes & CDDP/VP16/DXR & $\mathrm{CR}$ & DG & $\begin{array}{l}\text { Peritoneum, } \\
\text { para-aortic LN }\end{array}$ & DOD & 18 & (8) \\
\hline 25 & 1999 & $54 / \mathrm{M}$ & LD (advanced) & No & CDDP/VP16 & PR & TG, splenectomy & Liver, lung & DOU & 7 & (20) \\
\hline 26 & 2003 & $58 / \mathrm{M}$ & ED & No & CDDP/VP16/5-FU & PR? & $\begin{array}{l}\text { TG, splenectomy, } \\
\text { hepatectomy, } \\
\text { pancreatectomy }\end{array}$ & $\begin{array}{l}\text { Liver, pancreas, } \\
\text { colon, spleen, } \\
\text { peritoneum }\end{array}$ & DOD & 8 & (21) \\
\hline 27 & 2003 & $48 / \mathrm{M}$ & ED & No & Carboplatin/VP16 & PR? & $\begin{array}{l}\text { TG, esophago- } \\
\text { jejunostomy }\end{array}$ & $\begin{array}{l}\text { Liver, colon, } \\
\text { kidney }\end{array}$ & DOD & 7 & (22) \\
\hline \multirow[t]{2}{*}{28} & 2004 & 73/M & ED & ND & i) CDDP/irinotecan & PR & & Liver & & & \\
\hline & & & & & ii) CDDP/VP16 & CR & $\begin{array}{l}\text { TG (for adeno- } \\
\text { carcinoma) }\end{array}$ & & Alive, NED & $\geq 24$ & (3) \\
\hline 29 & 2004 & $64 / \mathrm{M}$ & ED & ND & CDDP/VP16 & PR & RT & Brain & DOD & 9.2 & (23) \\
\hline 30 & 2004 & $75 / \mathrm{M}$ & ED & ND & CDDP/S-1 & PR & None & Liver & DOD & 14 & (24) \\
\hline \multirow[t]{2}{*}{31} & 2004 & $76 / \mathrm{F}$ & ED & No & $\begin{array}{l}\text { i) Neoadjuvant } \\
\text { CDDP/VP16 }\end{array}$ & PR & TG & $\begin{array}{l}\text { Liver, diaphragma, } \\
\text { clavicular and }\end{array}$ & & & \\
\hline & & & & & ii) PTX & PD & & para-aortic LN & DOD & 7 & (25) \\
\hline
\end{tabular}


Table I. Continued.

\begin{tabular}{|c|c|c|c|c|c|c|c|c|c|c|c|}
\hline $\begin{array}{l}\text { Case } \\
\text { no. }\end{array}$ & Year & Age/sex & Stage & $\begin{array}{l}\text { Adeno- } \\
\text { carcinoma } \\
\text { component }\end{array}$ & $\begin{array}{l}\text { Chemotherapeutic } \\
\text { regimen }\end{array}$ & Response & $\begin{array}{l}\text { Concomitant } \\
\text { treatment }\end{array}$ & $\begin{array}{l}\text { Site of metastasis } \\
\text { or recurrence }\end{array}$ & Status & $\begin{array}{l}\text { Follow-up } \\
\text { (month) }\end{array}$ & Refs \\
\hline 32 & 2005 & $52 / \mathrm{M}$ & LD (advanced) & No & CDDP/VP16 & & TG & None & Alive, NED & 36 & (26) \\
\hline 33 & 2005 & $72 / \mathrm{M}$ & LD (advanced) & Yes & $\begin{array}{l}\text { Neoadjuvant; } \\
\text { carboplatin/ } \\
\text { EPI/VP16/5-FU }\end{array}$ & PR & TG, splenectomy & Para-aortic LN & DOU & 43 & (2) \\
\hline \multirow[t]{2}{*}{34} & 2005 & $60 / \mathrm{M}$ & ED & ND & $\begin{array}{l}\text { i) } \mathrm{CDDP} / 5-\mathrm{FU} \\
\text { ii) } \mathrm{CDDP} / \text { irinotecan }\end{array}$ & $\begin{array}{l}\text { PD } \\
\text { PR }\end{array}$ & None & Liver, pancreas & & & \\
\hline & & & & & iii) S-1/irinotecan & PR & & & AWD & 8 & (27) \\
\hline \multirow[t]{2}{*}{35} & 2006 & $69 / \mathrm{M}$ & ED & ND & $\begin{array}{l}\text { i) } \mathrm{S}-1 / \mathrm{PTX} \\
\text { ii) } \mathrm{CDDP} / \text { irinotecan }\end{array}$ & $\begin{array}{l}\mathrm{PR} \\
\mathrm{NC}\end{array}$ & Jejunostomy, RT & $\begin{array}{l}\text { Pancreas, adrenal } \\
\text { gland, brain, LN }\end{array}$ & & & \\
\hline & & & & & iii) CDDP/VP16 & $\mathrm{NC}$ & & & AWD & 21 & (28) \\
\hline \multirow[t]{4}{*}{36} & 2006 & $28 / \mathrm{F}$ & ED & No & $\begin{array}{l}\text { i) CDDP/VP16/ } \\
\text { doxifluridine }\end{array}$ & ND & PG, hepatectomy & Liver & & & \\
\hline & & & & & $\begin{array}{l}\text { ii) DXR/MMC/5-FU/ } \\
\text { lipiodol }\end{array}$ & ND & & & & & \\
\hline & & & & & iii) CDDP using HAI & PR & & & & & \\
\hline & & & & & iv) $\mathrm{CDDP} / 5-\mathrm{FU}$ & $\mathrm{CR}$ & & & AWD & $\geq 84$ & (9) \\
\hline
\end{tabular}

ED, extensive disease (spread of disease beyond locoregional boundaries); LD, limited disease (limited in stomach including regional LN metastasis); ND, not described; CR, complete response; PR, partial response; NC, no change; PD, progressive disease; OS, overall survival; NED, no evidence of disease; AWD, alive with disease; DOD, died of disease; DOU, died of unknown cause; SG/TG/PG/DG, subtotal/total/partial/distal gastrectomy; RT; radiotherapy to brain; PBSCT, peripheral blood stem cell transplantation; hepatectomy; including lobectomy, segmentectomy and tumor resection; CDDP, cisplatin; 5-FU, 5-fluorouracil; CPA, cyclophosphamide; DXR, doxorubicin; EPI, epirubicin; MMC, mitomycin C; VCR, vincristine; PTX, paclitaxel.

Table I, based on previously reported literature. Similar to the current case and case 1, even early-stage cases reveal metastases soon after surgical resection (7). Therefore, even if the gastric EC is in the early stage, postoperative adjuvant chemotherapy should always be administered. While the anti-cancer agents used in chemotherapy for gastric ECs vary, platinum-based chemotherapies have been used in many cases, and occasionally excellent responses have been obtained $(3,8,9)$. Since there are biological similarities between stomach ECs and small cell lung carcinomas (SCLCs), chemotherapeutic regimens for SCLCs have often been applied towards stomach ECs. A combination of CDDP and VP16, which is a standard regimen for extensive SCLCs (10), demonstrates a high response against gastric ECs. In contrast to SCLCs, ECs of the stomach are often accompanied by a non-small cell component, such as an adenocarcinoma or a squamous cell carcinoma $(4,5,11)$. Therefore, careful attention should be paid to the choice of anti-cancer agents for composite-type gastric ECs, as chemosensitivities vary for each carcinoma cell type. Moreover, the beneficial responses after chemotherapy are mostly short and transient, and may be followed by another chemotherapeutic regimen.

In the current case, as the first recurrence was limited to the liver and the recurrent hepatic tumors progressed very quickly, HAI therapy was chosen, which led to the almost complete disappearance of the massive tumors. While a few documented cases with liver metastases treated by HAI therapy using CDDP have resulted in favorable responses (9), there are no reports showing almost complete responses after HAI therapy. In Japan, HAI chemotherapy with the continuous low-dose administration of CDDP and 5-FU (low-dose FP) (12) is frequently used to treat advanced, unresectable and multinodular forms of hepatocellular carcinoma (HCC). HAI with low-dose FP achieved more beneficial therapeutic results for these HCCs than transcatheter arterial chemoembolization $(13,14)$. In addition to its own effect, CDDP amplifies the cell-killing effect of 5-FU, and the combination of CDDP and 5-FU, is widely used in chemotherapy for esophageal, colorectal and ovarian carcinomas. Unlike the intravenous high-dose administration of chemotherapeutic agents, HAI therapy through an implanted port can deliver anti-cancer agents in high concentrations directly to the liver, thereby decreasing the therapy's adverse effects. In contrast, a combined administration of 5-FU, epirubicin and mitomycin $\mathrm{C}$ (FEM) through HAI has been established for the treatment of liver metastases from gastric carcinomas (15). FEM chemotherapy using HAI resulted in favorable responses against these metastatic liver tumors. Histologically, these stomach lesions are highly differentiated carcinomas, such as papillary, well-, and moderately-differentiated adenocarcinomas, in more than half of these cases. In contrast, advanced HCCs, which can be managed by HAI with low-dose FP, are composed of moderately to poorly differentiated carcinomas in most cases (16). For the above-mentioned reasons, we selected HAI therapy with low-dose FP, which proved to be a useful option to regionally treat metastatic liver tumors from gastric ECs. Unfortunately, in the present case, soon after the almost complete disappearance of the multiple liver tumors, extended and aggressive recurrences occurred, followed by liver failure and subsequent death in spite of systemic 
chemotherapy. Nevertheless, there is no doubt that the HAI therapy prolonged the patient's survival period.

In conclusion, we reported a case in which a subject with stomach EC, developed metastatic liver tumors, which were successfully treated by HAI therapy with low-dose FP. We reviewed previously published therapies for gastric ECs, and emphasized the importance of positive and intensive therapy even in cases of early-stage disease. Cumulative reports in the future are necessary to improve the bleak prognosis of gastric ECs.

\section{Acknowledgements}

The authors would like to thank Dr Naoki Hosaka, from The Department of Pathology, Kansai Medical University, for his support in the histological diagnosis.

\section{References}

1. Brenner B, Tang LH, Klimstra DS, et al: Small-cell carcinomas of the gastrointestinal tract: A review. J Clin Oncol 22: 2730-2739, 2004.

2. Nakamura Y, Otani S, Otaka M, et al: Gastric small cell carcinoma with marked response to neoadjuvant chemotherapy. Int J Clin Oncol 10: 348-352, 2005

3. Hosokawa A, Shimada Y, Shirao K, et al: Long-term survivor of gastric small cell carcinoma. Hepatogastroenterology 51: 1567-1570, 2004

4. Matsui K, Kitagawa M, Miwa A, et al: Small cell carcinoma of the stomach: A clinicopathologic study of 17 cases. Am J Gastroenterol 86: 1167-1175, 1991.

5. Kusayanagi S, Konishi K, Miyasaka N, et al: Primary small cell carcinoma of the stomach. J Gastroenterol Hepatol 18: 743-747, 2003.

6. Tanemura H, Ohshita H, Kanno A, et al: A patient with smallcell carcinoma of the stomach with long survival after percutaneous microwave coagulating therapy (PMCT) for liver metastasis. Int J Clin Oncol 7: 128-132, 2002.

7. Fukuda T, Ohnishi Y, Nishimaki T, et al: Early gastric cancer of the small cell type. Am J Gastroenterol 83: 1176-1179, 1988.

8. Hirama K, Tsuchida H, Matsumoto K, et al: Two cases of gastric small cell carcinoma responding to postoperative chemotherapy with modified EAP regimen. J Jpn Soc Clin Surg 59: 983-989, 1998.

9. Shirado A, Uto H, Kusumoto K, et al: A case of gastric endocrine cell carcinoma with liver metastasis showing rapid growth during pregnancy and marked reduction by systemic chemotherapy after delivery. Nippon Shokakibyo Gakkai Zasshi 103: 827-832, 2006.

10. Noda K, Nishiwaki Y, Kawahara M, et al: Irinotecan plus cisplatin compared with etoposide plus cisplatin for extensive small-cell lung cancer. N Engl J Med 346: 85-91, 2002.

11. Hussein AM, Otrakji CL and Hussein BT: Small cell carcinoma of the stomach. Case report and review of the literature. Dig Dis Sci 35: 513-518, 1990.

12. Ando E, Yamashita F, Tanaka M, et al: A novel chemotherapy for advanced hepatocellular carcinoma with tumor thrombosis of the main trunk of the portal vein. Cancer 79: 1890-1896, 1997.
13. Okuda K, Tanaka M, Shibata J, et al: Hepatic arterial infusion chemotherapy with continuous low dose administaration of cisplatin and 5-fluorouracil for multiple recurrence of hepatocellular carcinoma after surgical treatment. Oncol Rep 6: 587-591, 1999.

14. Sumie S, Yamashita F, Ando E, et al: Interventional radiology for advanced hepatocellular carcinoma: comparison of hepatic artery infusion chemotherapy and transcatheter arterial lipiodol chemoembolization. Am J Roentogenol 181: 1327-1334, 2003.

15. Kumada T, Arai Y, Itoh K, et al: Phase II study of combined administration of 5-fluorouracil, epirubicin and mitomycin-C by hepatic artery infusion in patients with liver metastases of gatric cancer. Oncology 57: 216-223, 1999.

16. Sugihara S, Nakashima O, Kojiro M, et al: The morphologic transition in hepatocellular carcinoma - a comparison of the individual histological features disclosed by ultrasound-guided fine-needle biopsy with those of autopsy. Cancer 70: 1488-1492, 1992.

17. Masuyama K, Oonishi Y, Sawataishi M, et al: A case of small cell carcinoma of the stomach with multiple liver metastases. Gan To Kagaku Ryoho 21: 2338-2340, 1994.

18. Sakai K, Nomura H, Nogami T, et al: A case of complete remission of gastric endocrine cell carcinoma with multiple bone metastasis by combination chemotherapy and high-dose chemotherapy with autologous peripheral blood stem cell transplantation. Gan To Kagaku Ryoho 24: 2277-2280, 1997.

19. O'Byrne KJ, Cherukuri AK, Khan MI, et al: Extrapulmonary small cell gastric carcinoma. A case report and review of the literature. Acta Oncol 36: 78-80, 1997.

20. Futagami F, Asano K, Matsumura A, et al: A case of small cell carcinoma of the stomach with multiple liver and lung metastases successfully treated by combined chemotherapy with cisplatin and etoposide. Gan To Kagaku Ryoho 26: 149-152, 1999.

21. Hosoya Y, Nagai H, Koinuma K, et al: A case of aggressive neuroendocrine carcinoma of the stomach. Gastric Cancer 6: 55-59, 2003

22. Chaudhary UB, Taksey JD, Johnson RD, et al: Small-cell cancers, and an unusual reaction to chemotherapy: Case 3. Smallcell carcinoma of the stomach. J Clin Oncol 21: 2441-2442, 2003.

23. Kim JH, Lee S-H, Park J, et al: Exrapulmonary small-cell carcinoma: a single institution experience. Jpn J Clin Oncol 34: 250-254, 2004.

24. Shimada M, Iwase H, Iyo T, et al: A case of complete response in a primary lesion treated by combined chemotherapy of TS-1 and CDDP for small cell carcinoma of the stomach with liver metastasis. Gan To Kagaku Ryoho 31: 593-596, 2004.

25. Hasegawa K, Maruyama M, Takashima I, et al: A case of gastric endocrine cell carcinoma with neck lymph node metastasis resected after neoadjuvant chemotherapy. Gan To Kagaku Ryoho 31: 1935-1938, 2004.

26. Namikawa T, Kobayashi M, Okabayashi T, et al: Primary gastric small cell carcinoma: report of a case and review of the literature. Med Mol Morphol 38: 256-261, 2005.

27. Kato T, Sato K, Tamahashi N, et al: A case of small cell carcinoma of the stomach. Gan To Kagaku Ryoho 32: 1473-1475, 2005.

28. Saeki H, Anegawa G, Masuda T, et al: A case of inoperable gastric small cell carcinoma effectively treated by chemotherapy and radiotherapy. Gan To Kagaku Ryoho 33: 977-979, 2006. 